\title{
Bioavailability of Beta Carotene in Traditional Fermented, Roasted Granules, Gari from Bio-Fortified Cassava Roots
}

\author{
Olapeju O. Phorbee\#, Ibiyemi O. Olayiwola, Silifat A. Sanni
}

Department of Nutrition and Dietetics, Federal University of Agriculture, Abeokuta, Nigeria.

Email: "olapejubusola@yahoo.com

Received September $16^{\text {th }}, 2013$; revised October $16^{\text {th }}, 2013$; accepted October $23^{\text {rd }}, 2013$

Copyright (C) 2013 Olapeju O. Phorbee et al. This is an open access article distributed under the Creative Commons Attribution License, which permits unrestricted use, distribution, and reproduction in any medium, provided the original work is properly cited. In accordance of the Creative Commons Attribution License all Copyrights (C) 2013 are reserved for SCIRP and the owner of the intellectual property Olapeju O. Phorbee et al. All Copyright (C) 2013 are guarded by law and by SCIRP as a guardian.

\begin{abstract}
Vitamin A Deficiency (VAD) is a major public health issue and of global concern, as it affects millions of preschool children and pregnant women worldwide. Bio-fortification has emerged as a technology with potential to sustainably alleviate VAD especially in the sub-Saharan Africa, using staples like cassava. This work studied bioavailability of beta carotene (BC) in two processed gari samples from bio-fortified cassava varieties: 01/1412 and 01/1371, using 40 weanling albino rats, grouped into four, acclimatized for 1 week and fed experimentally for 4 weeks. Plasma beta carotene (PBC) was determined with HPLC while bioavailable BC calculated using conventional linear dose response plot. The mean rat weight gain was $5.3 \mathrm{~g}$ with significant difference $(\mathrm{p}<0.001)$ among them while mean $\mathrm{PBC}$ was 60.5 and $61.2 \mu \mathrm{g} / \mathrm{dL}$ for $01 / 1412$ and $01 / 1371$ respectively. From this study, a large variation of PBC among animals was found with a weak linear relationship between feed and $\mathrm{PBC}$, showing that BC bioavailability is not limited to intake. The BC bioavailability of the samples was between $11 \%$ and $18 \%$ with sample from variety $01 / 1371$ recording higher percentage (18\%). Gari from bio-fortified cassava roots processed traditionally, had appreciable bioavailable BC, which can contribute to the fight against VAD and improve nutritional status in developing countries although the magnitude of the problem requires a combination of strategies, of which bio-fortification is just one. However, further work is necessary on public awareness and adoption of the product.
\end{abstract}

Keywords: Bioavailability; Bio-Fortification; Beta-Carotene; Cassava; Gari

\section{Introduction}

Vitamin A deficiency is a major public health issue and of global concern. According to the World Health Organization report [1], Africa has the second highest prevalence of Vitamin A deficiency after South-East Asia. Vitamin A deficiency (VAD) affects approximately 127 million preschool children and more than 7.2 million pregnant women worldwide [2]. It causes impaired vision in many areas of the developing world and it is the leading cause of acquired blindness in children [1]. Public health interventions to address vitamin A deficiency include fortification of flour with vitamin A and supplementation (twice yearly vitamin A capsules for preschool

*Funds for this study was self provided. Cassava samples, processing facilities and plant analyses were provided by the International Institute of tropical Agriculture, Nigeria.

${ }^{\#}$ Corresponding author. children) as well as dietary diversification [3]. Each of these approaches has been reported to be beneficial to vulnerable and at risk groups although with some shortcomings, which limit their impact [4]. Recently, biofortification emerged as a technology with potential to sustainably alleviate VAD in an efficient manner and complement the strategies already adopted especially in the developing sub-Saharan Africa where people live on staples. However, to make appreciable impact, it is necessary to consider the concentration of provitamin A in bio-fortified food, the factors of bioavailability and bioconversion of nutrients, beyond the effects of used processing. Cassava (Manihot esculanta, Crantz) is one of the staples targeted for bio-fortification as it is consumed daily by populations in Sub-Saharan Africa. It has been estimated that 70 million people in Africa obtain more than $500 \mathrm{kcal} /$ day from cassava and major source of die- 
tary energy for low-income consumers in many parts of tropical Africa, including major urban areas [5].

Studies have been reported on bio-fortification of cassava and cassava products ranging from product development to carotenoid retention in processing, storage and consumer acceptability [6-8]. However, bioavailability of nutrient in cassava and cassava products from the biofortified varieties becomes important in view of diverse nature of the Nigerian consumers home and abroad although Falia and Chitchumroonchokchai [9] reported a study on bioavailability of boiled roots. Detailed knowledge of bioavailability in consumption of cassava products from bio-fortified cassava roots is pre requisite of predicting the efficacy of bio-fortification in combating vitamin A deficiency. This study therefore looked into the bioavailability of beta carotene in gari, traditional fermented roasted granules processed under optimal conditions of carotenoid retention.

\section{Objective}

The main objective of the study was to assess the bioavailability of beta carotenoid in Gari from bio fortified yellow fleshed cassava roots

\section{Materials and Methods}

\subsection{Materials}

\section{Source of Raw Material}

Two samples of gari from two bio-fortified cassava varieties processed at varied conditions for optimal carotenoid retention and consumer acceptability, studied earlier were used for the study. The samples were from biofortified varieties $01 / 1412$ and $01 / 1371$, both fermented for 1 day and roasted at $80^{\circ} \mathrm{C}$ and $120^{\circ} \mathrm{C}$ respectively.

\subsection{Methodology}

\subsubsection{Gari Production}

The Gari samples used were produced, using the typical traditional processing methods although controlled for carotenoid retention. The grated cassava mash from the 2 varieties; 01/1412 and 01/1371 was fermented for 1 day each roasted at $80^{\circ}$ and $120^{\circ}$ Celsius respectively. The standardized procedure involved peeling freshly harvested bio-fortified cassava roots with stainless steel knife, washed thoroughly with potable water to remove all dirt and adhering sand particles. The peeled, washed cassava roots were grated into mash using a petrol engine driven stainless grater, packed into Hessian sacks and left for 1 day, in fermentation trough to ferment after which the fermented mash was pressed using a hydraulic press to remove moisture until cake formed (about $40 \%-50 \%$ moisture). The fermented cakes were sieved manually with stainless steel sieve to pulverize the cake and sepa- rate fibrous materials. The pulverized cake was then roasted in a large, shallow stainless steel pan at the selected temperatures, with constant stirring until cream, free-flowing granules were obtained. The final Gari was spread on a stainless steel tray to cool and then sieved to obtain granules of uniform particle size before been packaged into polyethylene bags and stored at $-80^{\circ} \mathrm{Cel}-$ sius prior to laboratory analysis and further studies.

\subsubsection{Carotenoid Profile of the Gari Samples from Bio-Fortified Cassava Varieties (BFCV)}

The two gari samples were analyzed for Carotenoid profile using High Performance Liquid Chromatography, (HPLC) method of Harvestplus [10].

1) Carotenoid Extraction

Total Carotenoid contents (TCC) of the samples were determined using visible absorption spectrophotometry. Five grams of samples was weighed into a mortar, cellite powder and $15 \mathrm{ml}$ ethanol added for extraction, using grinding. Each sample was extracted three times to ascertain complete removal of carotenoid from the sample while vacuum pump was used to filter the extract. The combined extracts were rinsed with ethanol two times and acetone once. The extract was filtered using anhydrous substance and absorbance read at $450 \mathrm{~nm}$ in spectrophotometer and absorption coefficient (2592) of $\beta$ carotene in petroleum ether.

2) Carotenoid Quantification

For the HPLC determinations the organic phase used for spectrophotometric quantification of TCC, aliquots (15 mL) were transferred to a glass tube, and dried by nitrogen evaporator (N-Evap 112, Organomation Associates, Berlin, MA, USA). Immediately before injection, in the same tube, the dry extract was totally dissolved in 2.0 $\mathrm{mL}$ of $(1: 1)$ methanol and methyl tert-butyl ether $\mathrm{MeOH}$ : MTBE HPLC-grade after sonication (10 s) and agitation in a VWR multi-tube vortexer (2400 rpm; $60 \mathrm{~s})$, and filtered through a $0.22 \mu \mathrm{m}$ polytetrafluorothylene (PTFE) filter. Separation and quantification of carotenoids were achieved using an YMC Carotenoid S-5 C30 reversedphase column $(4.6 \mathrm{~mm} \times 150 \mathrm{~mm}$ : particle size, $5 \mu \mathrm{m})$, with a YMC Carotenoid S-5 guard column $(4.0 \times 23 \mathrm{~mm})$ in a HPLC system (Agilent Technologies 1200 series, Waldbronn, Germany), using DAD detector with three wavelengths set at $286 \mathrm{~nm}$ (for phytoene), $348 \mathrm{~nm}$ (for phytofluene) and $450 \mathrm{~nm}$ (for colored carotenoids). Peaks were identified by comparing retention time and spectral characteristics against a pure standard from $\mathrm{Ca}-$ roteNature $\mathrm{GmbH}$, Lupsingen, Switzerland: $\beta$-Cryptoxanthin- $\mathrm{N}^{\circ} 0055$ HPLC 97\%; $\beta$-Carotene-N ${ }^{\circ} 0003$ HPLC 96\%. 9-cis and 13-cis isomers of $\beta$-carotene were identified according to the following combined information: elution order, UV-visible spectrum ( $\lambda$ max, spectral fine structure, peak cis intensity). Their calibration was made 
using the/all-trans $\beta$-carotene curve. Quantity of each carotenoid was determined by integration of peak area against respective standard curves.

\subsubsection{Determination of Bioavailability of Carotenoids in Gari from Bio-Fortified Cassava Varieties}

1) Rats and Procedures

For this study, bioavailability of carotenoid in the two Gari samples were determined using rats according to the methods of Howe and Tanumihardjo [11] and Chandrika et al., [12] with few modifications intended to better determine the $\mathrm{BC}$ bioavailability in the rats. All protocols regarding the rat study was approved by the Department of Animal Science, University of Ibadan, Nigeria. Forty healthy male albino weanling rats of Wister strain and weight between $52 \pm 20$ gram were obtained from the Department of Animal Sciences of the University of Ibadan, Nigeria and acclimatized for one week. Rats were individually housed in stainless steel metabolic cages and fed ad lithium. After the acclimatization phase, all the rats were sorted into weight matched treatment groups of four in a $(4 \times 10)$ complete randomized block design (control, basal and two experimental feeding groups). The control group feed comprised of white Gari (from carotenoid-free cassava roots) as the principal energy source, casein as protein source, non-vitamin A fortified vegetable oil, wheat bran for dietary fiber, bone meal for minerals, pre-mix and dried carrot for carotenoid source. The basal diet has similar composition to that of control but without carrot. The experimental groups 3 and 4 consisted of Gari from white flesh cassava (no carotenoid) and each of the experimental samples of Gari from yellow fleshed cassava roots at ratio $1: 1$. The carrots used was also calculated and mixed to achieve an equalized $\mathrm{BC}$ concentration with the yellow fleshed Gari samples. Each group of rats was subjected to the feeding for four weeks while feed intake of each rat was taken daily by weighing fresh and remnant feed. Weights of rats were taken weekly while blood sampling was done fortnightly after one week acclimatization. A total of three sets of blood samples were collected in the study; at the beginning of the feeding after acclimatization, mid-way into the feeding and after the study. At the end of the study, all the rats were killed and liver taken for vitamin A analysis (bioconversion).

2) Serum Isolation and Liver Sample Processing

Blood samples were centrifuged 2200 part per million for 15 minutes in BD Vacutainer Gel and Clot Activator tubes for serum isolation. Livers of the rats were excised and stored at $-80^{\circ}$ Celsius prior to analysis. All animal handling procedures were approved by the University of Ibadan-Departments of Animal Science and Physiology.

The plasma samples were analyzed for beta-carotene and vitamin A respectively using HPLC at the University College Hospital Laboratory, University of Ibadan, Nigeria.

\subsubsection{Rat Feed Composition for Bioavailability Study of BC in GBFCV}

The composition of feed for the different four groups of the rat is as shown in the Table $\mathbf{1 .}$

Determination of Plasma Beta Carotene (PBC) of the Studied Rats.

The method described by Shi et al. [13] was used in determining the PBC content of the rats fed with yellow fleshed Gari diets. $0.2 \mathrm{ml}$ serum sample was pipetted into a set of sterile graduated beakers. $10 \mathrm{ml}$ of extraction solvent was added and mixed properly. Extraction solvent is a mixture of $0.1 \%$ of quinol plus acetone and light petroleum. The supernatant was transferred to a separating

Table 1. Feed composition of the four groups of rats used in the study.

\begin{tabular}{|c|c|c|c|c|c|c|}
\hline Nutrients & Sources & $\%$ & Group 1: Control (kg) & Group 2: Basal (kg) & Group 3: "EGS 1 (kg) & Group 4: "EGS 2 (kg) \\
\hline Energy & White Gari & 72 & 3.6 & 3.6 & 1.8 & 1.8 \\
\hline Protein & Casein & 10 & 0.5 & 0.5 & 0.5 & 0.5 \\
\hline Fat & Vegetable oil & 8 & 0.4 & 0.4 & 0.4 & 0.4 \\
\hline Dietary fiber & Wheat Bran & 5 & 0.25 & 0.25 & 0.25 & 0.25 \\
\hline Minerals & Bone meal & 4 & 0.20 & 0.20 & 0.20 & 0.20 \\
\hline Vitamins & Pre-mix & 1 & 0.05 & 0.05 & 0.05 & 0.05 \\
\hline \multirow[t]{3}{*}{ Beta carotene } & Carrot & & 0.03 & - & - & - \\
\hline & EGS 1 & & - & - & 1.8 & - \\
\hline & EGS 2 & & & & & 1.8 \\
\hline Total & & 100 & 5.0 & 5.0 & 5.0 & 5.0 \\
\hline
\end{tabular}

${ }^{*}$ Experimental Gari samples. 
funnel containing $5 \mathrm{ml}$ ultra-pure water after shaking for $10 \mathrm{~min}$. Another $10 \mathrm{ml}$ of ultra pure water was added and shaken to dilute acetone in the supernatant solution light petroleum solution from which the acetone had been removed was then transferred to the top of the column while gentle suction was applied to assist the passage of the liquid through the column. The beta carotene passed straight through the column, leaving all other fractions absorbed on top of the column. Light petroleum was then used to rinse the column to ensure complete removal of the BC. (Colorlessness of the eluate was an indicator of complete elution.) The sample solution was made up to $25 \mathrm{ml}$ column while it was stored for use for BC analysis using HPLC.

All samples were analyzed under gold fluorescent light to prevent photo-oxidation and isomerization.

\subsubsection{Calculation of Bioavailable Beta Carotene (BC)}

The bio availability was calculated using a conventional linear dose response plot. Concentration of $\mathrm{BC}$ in diet was on $\mathrm{x}$ axis while the $\mathrm{y}$ axis has the concentration of plasma BC. The slope was then calculated in percentage.

\subsubsection{Determination of Vitamin A (Retinol) in the} Liver of Rats Fed with Bio-Fortified Gari Diets Sample Extraction for Vitamin A (Retinol) Determination

0.5 gram of the liver samples were ground, homogenized with $1.15 \%$ potassium chloride and then mixed with $9 \mathrm{ml}$ hexane-2 propanol (2:3). $0.125 \mu \mathrm{L}$ of the liver sample was measured into a set of clean test tubes and made to $500 \mu \mathrm{L}$ volume with ultra pure water. $1.0 \mathrm{~g} / \mathrm{L}$ of ascorbic acid was added as an antioxidant and shaken for $5 \mathrm{~min}$ followed by another $5 \mathrm{~min}$ sonication. To the mixture, $0.5 \mathrm{~g} / \mathrm{L}$ of Triton (a detergent) and $400 \mu \mathrm{L}$ acetonitrile was added and thoroughly mixed. This acted as the internal standard. Also, $400 \mu \mathrm{L}$ n-hexane was measured and added. (This contained $5 \mathrm{~g} / \mathrm{L}$ BHT). The mixture was vigorously shaken for $4 \mathrm{~min}$ and centrifuged for $2 \mathrm{~min}$ at $8000 \mathrm{rpm}$. The supernatant was collected for Vitamin A (Retinol determination in HPLC).

Sample extracts were injected into the HPLC. The separation was carried out, using BDS Hypersil CN 150 $\mathrm{mm}, 5 \mu \mathrm{m}$ columns in combination with a javeln $\mathrm{NH}_{2}$ guard column. The isocratic mobile phase consisted of hexane isopropanol (98.5:1.5). The flow was fixed at a rate of $1.5 \mathrm{~mL} / \mathrm{min}$ while the wavelength was set at 325 $\mathrm{nm}$. Diode array detector was used to check the purity of the peaks.

\subsubsection{Calculation of Hepatic Retinol Conversion (HRC)}

The HRC was calculated in percentage of the slope of graph of liver retinol versus $\mathrm{BC}$ in feed. Concentration of $\mathrm{BC}$ in diet was on $\mathrm{x}$ axis while the $\mathrm{y}$ axis has the concentration of retinol in the liver of the rats.

\subsubsection{Statistical Analysis}

Values are means \pm SD. Data was analyzed using statistical Analysis Software (SAS version 9.5). Outcome of interests were rat weight gain, rat feed intake, plasma beta carotene, and liver vitamin A. Beta carotene concentrations were evaluated using 1-way ANOVA. Differences between treatment groups were determined using least significant differences, LSD at $\alpha<0.05$. A correlation between rat plasma and feed $\mathrm{BC}$ was also determined with Pearson correlation analysis.

\section{Results}

\subsection{Carotenoid Concentration of Gari Samples and Carrots Used for Bioavailability Study}

No beta carotene was detected in the white Gari used for the study and the basal diet. The carotenoid profile in the two Gari samples used for the bioavailability study is as shown in the Table 2. The two samples were not significantly different from each other in terms of carotenoid profile. The 13-cis isomers for sample from 01/1412 and $01 / 1371$ were $0.88 \mu \mathrm{g} / \mathrm{g}$ and $0.85 \mu \mathrm{g} / \mathrm{g}$ respectively. Also, 15 -cis isomers were $0.28 \mu \mathrm{g} / \mathrm{g}$ and $0.26 \mu \mathrm{g} / \mathrm{g}$ respectively. The same trend was found in other carotenoid.

The carotenoid profile of the carrot was relatively higher than those of bio-fortified cassava roots. The Bcryptoxanthin was $1.2 \mu \mathrm{g} / \mathrm{g}$ while the 13-cis and 15-cis $\mathrm{BC}$ were $104.4 \mu \mathrm{g} / \mathrm{g}$ and $3.34 \mu \mathrm{g} / \mathrm{g}$ respectively. For the trans isomer, it was $167.3 \mu \mathrm{g} / \mathrm{g}$ and that of 9-cis was 5.95 $\mu \mathrm{g} / \mathrm{g}$. The total BC in the carrot used (on fresh weight basis) was $84.23 \mu \mathrm{g} / \mathrm{g}$.

Table 2. Mean beta carotenoid profile of carrot and the gari samples used for bioavailability study.

\begin{tabular}{ccccccc}
\hline S/N & B-cryptoxanthin & 13-cis & $\boldsymbol{\beta}$ carotene 15-cis & Trans & 9-cis & Total BC \\
\hline Conc $(\boldsymbol{\mu g} / \mathbf{g})$ & 0.88 & 0.28 & 2.01 & 1.59 & 4.76 \\
\hline $01 / 1412$ fermented for 1 day \& roasted at $80^{\circ} \mathrm{C}$ & 0.89 & 0.85 & 0.26 & 1.97 & 1.56 & 4.64 \\
$01 / 1371$ fermented for 1 day \& roasted at $120^{\circ} \mathrm{C}$ & 0.93 & 104.40 & 3.34 & 167.3 & 5.95 & 84.23 \\
Carrots & 1.20 & & & & & \\
\hline
\end{tabular}




\subsection{Results of the Bioavailability Study}

\subsubsection{Mean Weekly Rat Weight Gain and Feed Intake}

All the animals in their various groups gained weight all through the study irrespective of feed composition of each group. The mean rat weight gain across the group was $5.3 \mathrm{~g}$ and ranged from 4 to $7 \mathrm{~g}$ with significant difference $(p<0.001)$ in their weight gain.

Across the group and over the study period, the feed mean weekly intake was $55 \mathrm{~g}$ and ranged from 47 to 67 gram. Statistically, there was a difference $(p<0.001)$ in intake among the rats. Rat weight gain was correspon- dent to feed intake across the groups; the more the intake, the more the rat weight gain and vice versa. Table 3 shows the summary of the mean weight gain and food intake across the groups.

\subsubsection{Mean Feed and Plasma BC Concentration}

The mean feed BC was $114 \mu \mathrm{g} / \mathrm{g}, 112 \mu \mathrm{g} / \mathrm{g}$ and $113 \mu \mathrm{g} / \mathrm{g}$ for acclimatization, first and second 2 weeks respectively with significant difference across the groups of the animals. After the acclimatization week, the mean plasma beta carotene (PBC) was $64 \mu \mathrm{g} / \mathrm{dL}$ with a range of 61.4 to $68.5 \mu \mathrm{g} / \mathrm{dL}$ and the concentrations did not differ statistically across the groups as shown in Table 4. For the

Table 3. Mean of rats weight gain and feed intake across the groups during the experimental feeding.

\begin{tabular}{ccccccccccc}
\hline Group & W1 (g) & W2 (g) & W3 (g) & W4 (g) & Mean (g) & Fd1 (g) & Fd2 (g) & Fd3 (g) & Fd4 (g) & Mean (g) \\
\hline Control & 4.1 & 7.6 & 7.6 & 8.6 & 7.0 & 44.2 & 51.9 & 53.2 & 54.4 & 49.4 \\
Basal & 3.3 & 5.2 & 6.3 & 7.3 & 5.5 & 63.5 & 69.3 & 64.7 & 65.6 & 66.7 \\
Experimental 1 & 1.8 & 3.9 & 4.2 & 6.1 & 4.0 & 51.3 & 58.5 & 53.9 & 53.6 & 55.5 \\
Experimental 2 & 2.4 & 3.0 & 6.0 & 7.8 & 4.8 & 48.3 & 56.6 & 48.2 & 55.4 & 51.6 \\
Means & 2.9 & 4.9 & 6.0 & 7.5 & 5.3 & 51.82 & 59.1 & 55.0 & 57.3 & 55.8 \\
Min & 1.8 & 3.0 & 4.2 & 6.1 & 4.0 & 44.2 & 51.9 & 48.2 & 53.6 & 48.2 \\
Max & 4.1 & 7.6 & 7.6 & 8.6 & 7.0 & 63.5 & 69.3 & 64.7 & 65.6 & 66.7 \\
CV (\%) & 10.5 & 15.9 & 16.5 & 19.6 & & 16.4 & 19.8 & 22.4 & 20.0 & \\
LSD (0.05) & 5.6 & 9.4 & 10.4 & 13.2 & & 8.0 & 10.9 & 11.6 & 10.7 & ns \\
Pr. > F & $* *$ & $* *$ & $* *$ & $* *$ & & $* *$ & $* *$ & $* *$ &
\end{tabular}

${ }^{* *} \mathrm{p}=0.001, \mathrm{~ns}=$ not significant. W1, W2, W3 and W4 are the weight of rats in the first, second, third and fourth week of feeding respectively. Fd1, Fd2, Fd3 and Fd4 are the weekly food intake of rats in the first, second, third and fourth week.

Table 4. Mean of Beta Carotene (BC) in feed and plasma during the experimental feeding.

\begin{tabular}{|c|c|c|c|c|c|c|}
\hline Group & F12BC $(\mu \mathrm{g} / \mathrm{g})$ & F34BC ( $\mu \mathrm{g} / \mathrm{g})$ & Mean $(\mu \mathrm{g} / \mathrm{g})$ & BC1 $(\mu \mathrm{g} / \mathrm{dl})$ & BC2 $(\mu \mathrm{g} / \mathrm{dl})$ & Mean $(\mu \mathrm{g} / \mathrm{dl})$ \\
\hline Control & 86.5 & 96.9 & 74.1 & 69.9 & 51.5 & 60.9 \\
\hline Basal & 0 & 0 & 0 & 60.1 & 51.3 & 60 \\
\hline Exptl 1 & 185.8 & 181.9 & 194.6 & 59.8 & 58.1 & 60.5 \\
\hline Exptl 2 & 177.4 & 175.4 & 185.3 & 63.6 & 57.5 & 61.2 \\
\hline Means & 112.4 & 113.5 & 113.5 & 63.4 & 54.6 & 60.6 \\
\hline SD & 87.39 & 84.98 & 93.38 & 4.73 & 3.73 & 0.53 \\
\hline SE & 43.7 & 42.5 & 46.7 & 2.4 & 1.9 & 0.3 \\
\hline Min & 0 & 0 & 0 & 59.8 & 51.3 & 57.5 \\
\hline Max & 185.8 & 181.9 & 194.6 & 69.9 & 58.1 & 65.5 \\
\hline CV (\%) & 21.2461 & 23.4504 & & 13.3 & 27.9 & \\
\hline $\operatorname{LSD}(0.05)$ & 22.098 & 24.603 & & 7.87 & 14.2 & \\
\hline Pr. $>$ F & ** & ** & & * & $\mathrm{ns}$ & \\
\hline
\end{tabular}

${ }^{* *} \mathrm{p}=0.001,{ }^{*} \mathrm{p}=0.01, \mathrm{~ns}=$ not significant. $\mathrm{F} 12 \mathrm{BC}$ and $\mathrm{F} 34 \mathrm{BC}$ are the $\mathrm{BC}$ in feed taken during, first 2 wk and last 2 wk respectively. BC1 and $\mathrm{BC} 2$ are the $\mathrm{BC}$ in the rat plasma after first $2 \mathrm{wk}$ and last $2 \mathrm{wk}$ respectively. 
basal group, $\mathrm{PBC}$ maintained a consistent drop since the feed was deficient in BC. However, for the two experimental groups, the mean PBC after the four week feeding was 60.5 and $61.2 \mu \mathrm{g} / \mathrm{dL}$ for $01 / 1412$ and $01 / 1371 \mathrm{re-}$ spectively. No significant difference was found in the PBC of the two samples. On the association between feed and plasma $\mathrm{BC}$, a very weak linear relationship was found (Table 5).

\subsection{Bioavailability and Relative Bioavailability}

Figures 1-3 show result of the $\mathrm{BC}$ bioavailability in form of linear dose response plots of the $\mathrm{BC}$ concentration of the feed consumed by the rats and that of the plasma for acclimatization using carrots and the experimental feeds from samples 01/1412 and 01/1371 respectively.

Table 6 shows the result of Bioavailability of BC in GFBCR across the two varieties. The mean bioavailability was between $8.5 \%$ and $17.4 \%$, and a significant difference $(\mathrm{p}<0.05 \%)$ was found between the two studied samples with that of variety $01 / 1371$ was higher (17.4\%).

\section{Discussion}

The carotenoid profile of the two gari samples is noteworthy for its high trans $\mathrm{BC}$ content, biosynthesis of each

Table 5. Pearson correlation coefficients of plasma and feed BC.

\begin{tabular}{cccc}
\hline & F0BC & F12BC & F34BC \\
\hline BC0 & -0.17625 & -0.16817 & -0.18441 \\
& 0.2898 & 0.3129 & 0.2677 \\
BC1 & -0.10557 & -0.07716 & 0.05562 \\
& 0.5282 & 0.6452 & 0.7401 \\
BC2 & 0.19504 & 0.11509 & 0.12906 \\
& 0.2406 & 0.4914 & 0.4400 \\
\hline
\end{tabular}

$\mathrm{N}=38$.

Table 6. Bioavailability and liver yield of $\mathrm{BC}$ in the rat groups.

\begin{tabular}{cccccc}
\hline Groups & $\begin{array}{c}\text { BAV after } \\
\text { 1st 2 wk (\%) }\end{array}$ & $\begin{array}{c}\text { BAV after } \\
\text { 2nd 2 wk }\end{array}$ & $\begin{array}{c}\text { Mean } \\
\text { BAV }\end{array}$ & RBAV & $\begin{array}{c}\text { Liver } \\
\text { yield }\end{array}$ \\
\hline Control & 29.30 & 46.60 & 37.95 & 100 & 0.120 \\
Basal & 0.00 & 0.00 & 0.00 & 000 & 0.020 \\
$\begin{array}{c}\text { Experimental } \\
\text { diet 1 }\end{array}$ & 6.26 & 10.80 & 8.53 & 0.22 & 0.026 \\
$\begin{array}{c}\text { Experimental } \\
\text { diet 2 }\end{array}$ & 18.45 & 16.44 & 17.44 & 0.46 & 0.011 \\
\hline
\end{tabular}

1. $01 / 1412$ fermented for I day \& roasted at $80^{\circ} \mathrm{C} ; 2.01 / 1371$ fermented for I day \& roasted at $120^{\circ} \mathrm{C}$; BAV: Bioavailability.

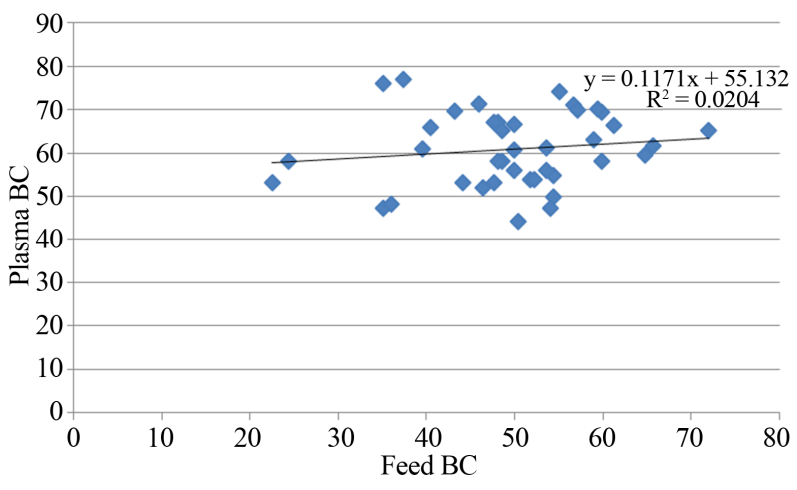

Figure 1. Graph of plasma BC Vs feed BC of the rats at acclimatization.

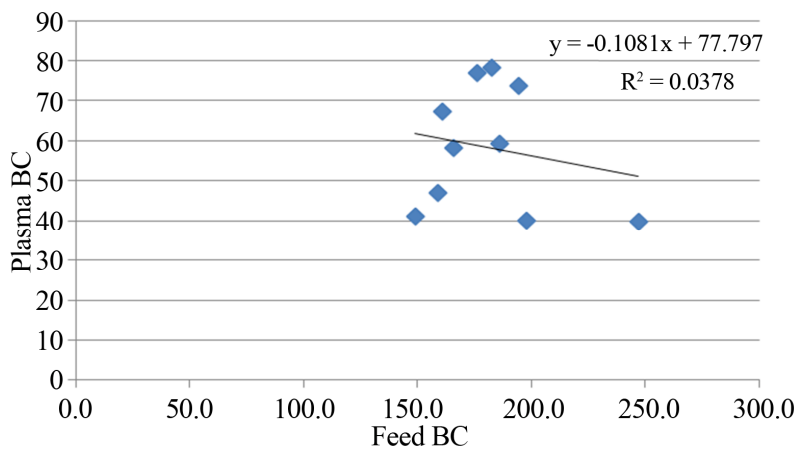

Figure 2. Graph of plasma BC Vs feed BC of the rats in diet from BFCV of Gari sample 1 (01/1412 fermented for 1 day and roasted at $80^{\circ} \mathrm{C}$ ).

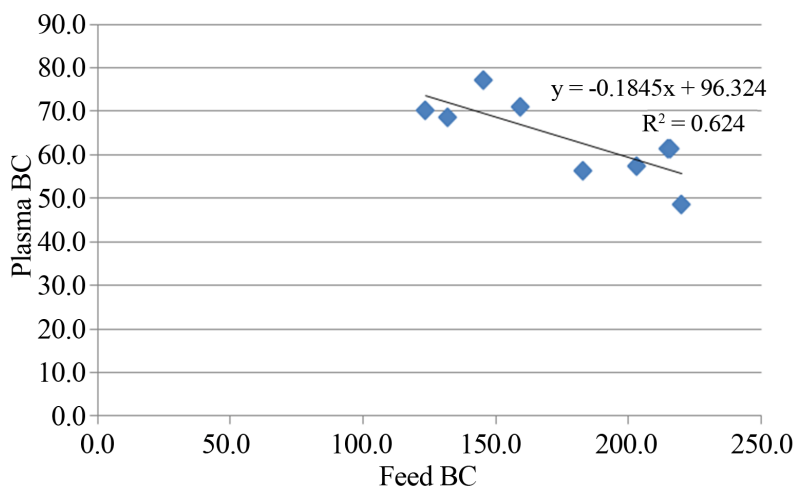

Figure 3. Graph of plasma BC Vs feed BC of the rats in diet from BFCV of Gari sample $1(01 / 1371$ fermented for 1 day and roasted at $120^{\circ} \mathrm{C}$ ).

of its 5 major carotenoids is likely to be up regulated in these varieties since $\mathrm{BC}$ is the precursor of beta cryptoxanthin and zexanthin [14]. Also, there was an appreciable percent of $\mathrm{BC}$ in the total carotenoid, which agreed with Chavez et al., [15]. This is advantageous in bio-accessibility of the carotenoid from cassava and a promising attribute of cassava as a vehicle to fight vitamin A deficiency challenge in Africa, where cassava is a staple crop. 
There was a strong linear relationship between feed intake and animal weight gain; this means that irrespective of $\mathrm{BC}$ content, the more the animal eat the food, the more their weight gain (the feed composition was adequate to maintain the animal weight gain) although the hidden hunger of vitamin A deficiency could still be evident.

From the bioavailability study, a large variation of PBC and hepatic retinol among animals within each group was found. This suggested a marked variability in $\mathrm{BC}$ utilization and efficiency of conversion of $\mathrm{BC}$ and storage of vitamin A among individual rats, which agreed with the report of Siqueira et al., [16]. The significant difference found in the bioavailability result of the two samples of gari showed the effect of cassava varieties in the bio-accessibility of pro-VA carotenoids for absorption. Gari from yellow-fleshed cassava root especially that from variety 01/1371 had appreciable level of bioavailable beta carotene, which could have been favored by the other nutrient components in the feed formulation [17]. Also fermentation of the cassava mash could have improved BC absorption, although short in this study. Fermentation provides an optimal pH for enzymatic degradation of phytate, which may increase the amount of soluble calcium, iron and Zinc [18] and then enhance that of BC. According to Hedren, et al. [19], when carotenoids are retained after processing, disruption of the plant matrix markedly enhances their potential for intestinal absorption (bio-accessibility). Grating and fermentation in gari processing had disrupted the food matrix thus easy bounding to protein and lipid molecules in the feed formulation, hence, improved $\mathrm{BC}$ absorption by rats $[16,20]$. However, it was observed that intake of the Gari-based feed could be increased if the feeds are presented in grits, bigger particle sizes or pellets rather than smooth and low particle size [17]. This may translate to increased bioavailability although the correlation between feed intake and plasma BC was found to be very weak. This shows that there are other factors, apart from intake that are responsible for nutrient bioavailability. These include types of carotenoid, molecular linkage, amount of carotenoids consumed in a meal, matrix in which the carotenoid is incorporated, effectors of absorption and bioconversion, nutrient status of the host, genetic factors, host-related factors, and mathematical interactions $[17,21]$. Also, there is a level that intake of the nutrient may not result in increased bioavailability. This is in agreement with the published reports [17,22]. The efficiency of carotenoid absorption is typically inefficient, being affected by structure of carotenoid, nature of the embedding matrix, level of dietary fat, nature and type of carotenoid, food matrix, style of processing, other dietary components, and nutritional and physiological status, presence of antioxidants and fibers. Thus, reliable pre- diction of carotenoid bioavailability is problematic. However, from this study, cassava beta-carotene could maintain rat growth and avoid vitamin A deficient symptoms. This also agreed with the report of Siqueira, et al. [16].

\section{Conclusion}

Gari from some bio-fortified cassava varieties especially that from 01/1371, processed at low temperature and short fermentation period had appreciable bioavailable $\mathrm{BC}$, which can maintain rat growth and prevent vitamin A deficient symptoms, beside the hepatic retinol recovery. This could be an important step to improve the nutritional quality of the popularly consumed Gari and to protect the health of the consumers. The relatively good retention of $\mathrm{BC}$ during traditional processing of cassava provides additional experimental support for the feasibility of cassava bio-fortification as a means to alleviate vitamin A deficiency. From the result of the bio-availability, cassava can be used as a sustainable vehicle to reduce vitamin A deficiency in the sub Saharan Africa. Bio-fortification is a promising new approach, which is technically feasible and the nutritionally enhanced foods can help to control micronutrient deficiencies. It could be an important tool for improving nutritional status in developing countries. Although, the magnitude of the problem requires a combination of strategies, of which biofortification is just one. However, further work is necessary on public awareness and adoption of the product while cassava breeders should target higher level of biofortification, taking cognizance of losses during processing and storage.

\section{Acknowledgements}

We thank the International Institute of Tropical Agriculture, Nigeria for providing the cassava roots and facilities for gari processing. Also, Dr(s). R. A. Sanusi, O. T. Adepoju and Folake Samuel of Department of Human Nutrition, University of Ibadan. Nigeria; the entire staff of the Department of Animal Sciences, University of Ibadan especially Mrs. Lawal and Mr. Idris. Finally, Ms. Seri Agbato amd Mr. Segun Dare for assisting in the rat study, and Mr. Moshood Bakare for the data analysis.

\section{REFERENCES}

[1] World Health Organization, "Quantifying Selected Major Risks to Health," The World Health Report 2002: Reducing Risks, Promoting Healthy Life, Geneva, 2002, pp. 47-97.

[2] K. P. West, "Extent of Vitamin A Deficiency among Preschool Children and Women of Reproductive Age," Journal of Nutrition, Vol. 132, Suppl. 9, 2002, pp. 2857S$2866 \mathrm{~S}$.

[3] FAO/ILSI, "Preventing Micronutrient Malnutrition: A 
Guide to Food-Based Approaches," Food and Agriculture Organization of the United Nations and International Life Science Institute, Washington DC, 1999, 9 p.

[4] World Health Organization/Food and Agriculture Organization, "Guidelines on Food Fortification with Micronutrients for the Control of Micronutrient Malnutrition," World Health Organization, Geneva, 2005, pp. 20-23.

[5] F. L. Nweke, D. S. C. Spencer and J. K. Lynam, "The Cassava Transformation: Africa's Best-Kept Secret," International Institute of Tropical Agriculture, Ibadan, 2002.

[6] O. O. Onadipe, "Total Carotenoid Content, Retention, Bioavailability and Consumer Acceptability of Gari from Bio-Fortified Cassava Roots," PhD Dissertation, Federal university of Agriculture, Abeokuta, 2011.

[7] O. O. Onabanjo, "Development and Nutritional Evaluation of Optimized Complementary Foods from Bio-Fortified Cassava Root and Leaves," PhD Dissertation, University of Agriculture, Abeokuta, 2007.

[8] B. B. Maziya-Dixon, A. G. O. Dixon and A. R. Adebowale, "Targeting Different End Uses of Cassava Genotypic Variations for Cyanogenic Potentials and Pasting Properties," International Journal of Food Science \& Technology, Vol. 42, No. 8, 2007, pp. 969-976.

[9] M. L. Falia and C. Chichumroonchokchai, "In Vitro Models as Tools for Screening the Relative Bioavailabilities of Pro Vitamin A Carotenoids in Foods," HarvestPlus Technical Monograph 3, 2005.

[10] M. Rodringuez-Amaya and Kimaya, "HarvestPlus Handbook for Carotenoid Analysis," HarvestPlus Technical Monograph 2, International Food Policy Research Institute (IFPRI) Washington DC and International Center for Tropical Agriculture (CIAT), Cali, 2004.

[11] J. A. Howe and S. A. Tanumihardjo, "Carotenoid-Biofortified Maize Maintains Adequate Vitamin A Status in Mongolian Gerbils," Journal of Nutrition, Vol. 136, No. 10, 2006, pp. 2562-2567.

[12] U. G. Chandrika, E. R. Jansz and N. D. Warnasuriya, "Analysis of Carotenoids in Ripe Jackfruit (Artocapus heterophyllus) Kernel and Study of Their Bioconversion in Rats," Journal of the Science of Food and Agriculture, Vol. 85, No. 2, 2005, pp. 186-190. http://dx.doi.org/10.1002/jsfa.1918

[13] A. H. Shi, Y. Ma, J. H. Humphrey and N. E. Craft, "Determination of Vitamin A in Dried Human Blood Spots by High Performance Capillary Electrophoresis with Laser-Excited Fluorescence Detection," Journal of Chromatography B: Biomedical Sciences and Applications,

\section{Abbreviations}

$B C$ : Beta Carotene;

PBC: Plasma Beta Carotene;

VAD: vitamin A deficiency;

HPLC: High Performance Liquid Chromatography;

TCC: Total Carotenoid Content
Vol. 665, No. 1, 1995, pp. 85-96. http://dx.doi.org/10.1016/0378-4347(94)00520-F

[14] L. F. Shanshan, A. K. Tayie, M. F. Young, S. Rocheford and W. S. White, "Retention of Provitamin A Carotenoids in High. Carotene Maize (Zea mays) during Traditional African Household Processing," Journal of Agricultural and Food Chemistry, Vol. 55, No. 26, 2007, pp. 1074410750. http://dx.doi.org/10.1021/jf071815v

[15] L. Chávez, T. Sánchez, H. Ceballos, D. B. RodriguezAmaya, P. Nestel, J. Tohme and M. Ishitani, "Retention of Carotenoids in Cassava Roots Submitted to Different Processing Methods," Journal of the Science of Food and Agriculture, Vol. 87, No. 3, 2007, pp. 388-393. http://dx.doi.org/10.1002/jsfa.2704

[16] E. M. Siqueira, S. F. Arruda, R. M. de Vargas and E. M. de Souza, "Beta-Carotene from Cassava (Manihot esculenta Crantz) Leaves Improves Vitamin A Status in Rats. Comparative Biochemistry and Physiology," Toxicology \& Pharmacology: CBP, Vol. 146, 2007, pp. 235-240.

[17] M. L. Failla, T. Huo and S. K. Thakkar, "In Vitro Screening of Relative Bioaccessibility of Carotenoids from Foods," Australia Asia Pacific Journal of Clinical Nutrition, Vol. 17, Suppl. 1, 2008, pp. 200-203.

[18] A. Blandino, M. E. Al-Aseeri, S. S. Pandiella, D. Cantero and C. Webb, "Cereal-Based Fermented Food and Beverages," Food Research International, Vol. 36, No. 6, 2003, pp. 527-543. http://dx.doi.org/10.1016/S0963-9969(03)00009-7

[19] E. Hedren, V. Dias and U. Swanberg, "Estimation of Carotenoid Accessibility from Carrots Determined by an in Vitro Digestion Method," European Journal of Clinical Nutrition, Vol. 56, No. 5, 2002, pp. 425-430. http://dx.doi.org/10.1038/sj.ejcn.1601329

[20] J. A. Howe, B. B. Maziya-Dixon and S. A. Tanumihardjo, "Cassava with Enhanced Beta-Carotene Maintain Adequate Vitamin A Status in Mongolian Gerbils (Meriones unguiculatus) Despite Substantial Cis-Isomer Content," British Journal of Nutrition, Vol. 102, No. 3, 2009, pp. 342-349. http://dx.doi.org/10.1017/S0007114508184720

[21] J. M. Castenmiller and C. E. West, "Bioavailability and Bio-Conversion of Carotenoid," Annual Review of Nutrition, Vol. 18, 1998, pp. 19-38.

[22] C. L. Rock, J. L. Lovalvo, C. Emenhiser, M. T. Ruffin, S. W. Flatt and S. J. Schwartz, "Bioavailability of $\beta$-Carotene Is Lower in Raw than in Processed Carrots and Spinach in Women," Journal of Nutrition, Vol. 128, No. 5, 1998, pp. 913-916.

BFCV: Bio-Fortified Cassava Varieties

GBFCV: Gari from Bio-fortified Cassava Varieties

HRC: Hepatic Retinol Conversion

LSD: Least Significant Difference

EGS: Experimental Gari Sample 